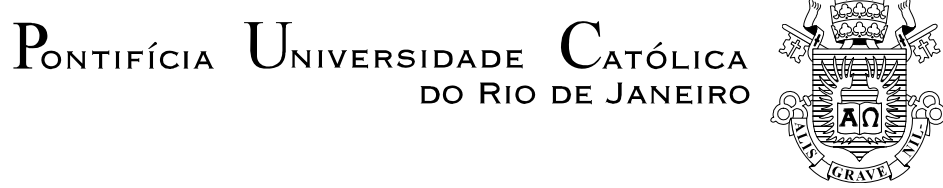

Helena Pinheiro Jucá-Vasconcelos

\title{
Violência Conjugal e Transmissão Psíquica Geracional
}

Dissertação de Mestrado

Dissertação apresentada ao Programa de PósGraduação em Psicologia Clínica da PUC-Rio como requisito parcial para obtenção do título de Mestre em Psicologia Clínica.

Orientadora: Profa. Terezinha Féres-Carneiro 


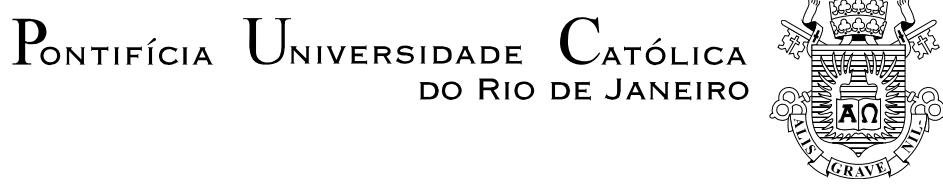

\section{Helena Pinheiro Jucá-Vasconcelos}

\section{Violência conjugal e Transmissão Psíquica Geracional}

Dissertação apresentada como requisito parcial para obtenção do grau de Mestre pelo Programa de Pós-Graduação em Psicologia Clínica da PUC-Rio. Aprovada pela Comissão Examinadora abaixo assinada.

Profa. Terezinha Féres-Carneiro

Orientadora

Departamento de Psicologia - PUC-Rio

Profa. Andrea Seixas Magalhães

Departamento de Psicologia - PUC-Rio

Profa. Edna Lúcia Tinoco Ponciano

UERJ

Profa. Denise Berruezo Portinari Coordenadora Setorial de Pós-graduação

E Pesquisa do Centro de Teologia e Ciências Humanas - PUC-Rio

Rio de Janeiro, 18 de março de 2011 
Todos os direitos reservados. É proibida a reprodução total ou parcial do trabalho sem autorização da universidade, da autora e do orientador.

\section{Helena Pinheiro Jucá-Vasconcelos}

Psicóloga e Bacharel em Psicologia pela Pontifícia Universidade Católica do Rio de Janeiro. Especialista em Psicologia Clínico-Institucional - Modalidade Residência - Hospital Universitário Pedro Ernesto / Universidade Estadual do Rio de Janeiro. Formada em Gestalt-terapia pelo Centro de Gestaltterapia Sandra Salomão. Possui experiência na área de Psicologia clínica, Psicologia hospitalar e em pesquisas no campo da Psicologia do desenvolvimento (PUC-Rio), da Psicologia da leitura (Universidad Autónoma de Madrid), da Neurociência e Psicanálise (PUC-Rio), da Psicolinguística (PUC-Rio), da família (UERJ) e da saúde (FIOCRUZ).

Ficha Catalográfica

Jucá-Vasconcelos, Helena Pinheiro

Violência conjugal e transmissão psíquica geracional / Helena Pinheiro Jucá-Vasconcelos ; orientadora: Terezinha Féres-Carneiro. - 2011.

112 f. ; $30 \mathrm{~cm}$

Dissertação (mestrado)-Pontifícia Universidade Católica do Rio de Janeiro, Departamento de Psicologia, 2011. Inclui bibliografia

1. Psicologia - Teses. 2. Violência conjugal. 3. Violência contra a mulher. 4. Transmissão psíquica geracional. I. Féres-Carneiro, Terezinha. II. Pontifícia Universidade Católica do Rio de Janeiro. Departamento de Psicologia. III. Título. 
Dedico essa dissertação aos meus pacientes, que dão sentido e amor ao meu trabalho. 


\section{Agradecimentos}

A elaboração deste trabalho não teria sido possível sem a cooperação, o estímulo e o comprometimento de diversas pessoas. Em primeiro lugar, gostaria de agradecer a Deus, por tudo que tenho e sou.

Gostaria de agradecer com carinho especial à professora Terezinha FéresCarneiro por sua atenção, orientação e amabilidade comigo.

Ao casal Maurício e Lígia Lintz, sou eternamente grata pelo apoio que me dão e me deram, sem o qual esse trabalho não teria sido executado.

Às participantes da pesquisa, agradeço pela disponibilidade, por confiarem em mim e por compartilharem suas histórias comigo.

À minha mãe, Lúcia Helena Pinheiro, e ao professor Fernando Campos por me auxiliarem quando precisei e pela demonstração de carinho e preocupação.

Não podia deixar de agradecer ao meu irmão Ricardo e minha cunhada Juliana pelo amor, carinho e suporte em todos os momentos. E também à minha família: pai, mãe, irmãos, tios e avós por suportarem minhas faltas e meu cansaço.

Agradeço aos meus amigos, que apesar da minha ausência, permaneceram presentes, em especial: Alice Cohen, Aline Zeque, Ana Beatriz de Castro, Clarice Palmeira, Cidiane Vaz, Cristiane Iatauro, Daniel Saito, Fernanda Vianna, Gabriela Paiva, Janaína Horácio, Jennifer Davis, Juliana Vasconcelos, Lívia Barboza, Luiza Medeiros, Máira Moreno, Maria Elizabeth Lopes, Patricia Bassan, Renata Cavour, Renata Fidelis, Roberta Rapuano, Taís Donati e Tereza Rausch.

Gostaria de dar um reconhecimento especial à Lucimara Rase, presente em todos os momentos, dos mais tristes aos mais importantes.

Queria expressar o meu agradecimento ao Edgardo Figueroa pela colaboração quando solicitei e por me motivar indiretamente a concluir o trabalho.

Agradeço à banca, Andrea Seixas Magalhães, Edna Lúcia Tinoco Ponciano e Lídia Levy pela disposição em avaliar minha dissertação. Assim como sou grata à PUC-Rio, aos professores, especialmente à Maria Elizabeth Ribeiro dos Santos, e a todos os funcionários do Departamento de Psicologia pelo suporte institucional. E também à Capes pelo financiamento, importante na realização dessa pesquisa.

Por fim, agradeço ao André Oberziner pelo apoio, carinho e amor, especialmente no momento de finalização e apresentação desse trabalho. 


\section{Resumo}

Jucá-Vasconcelos, Helena Pinheiro; Féres-Carneiro, Terezinha. Violência conjugal e Transmissão Psíquica Geracional. Rio de Janeiro, 2011, 112p. Dissertação de Mestrado - Departamento de Psicologia, Pontifícia Universidade Católica do Rio de Janeiro.

O presente trabalho buscou verificar as possíveis relações entre violência conjugal e transmissão psíquica geracional. Esse estudo é relevante pela alta prevalência da violência contra a mulher e por essa ser considerada problema de saúde pública. O objetivo principal deste trabalho foi investigar a possível transmissão da violência de uma geração à outra, identificando se houve a ocorrência da mesma também na família de origem e suas prováveis ressonâncias. Averiguou-se também que violências as vítimas sofreram e como as mesmas eram conceituadas por elas, assim como se buscou compreender como os abusos estavam presentes em suas vidas. Para alcançar os objetivos, realizou-se pesquisa de campo qualitativa, entrevistando nove mulheres vítimas de violência física de parceiros íntimos, através de entrevista por bate-papo na internet. O procedimento utilizado foi o Método de Explicitação do Discurso Subjacente (MEDS). Os resultados obtidos indicaram nítida repetição da violência entre os familiares, seja na posição de algoz, seja na de vítima.

\section{Palavras-chave}

Violência conjugal; violência contra a mulher; transmissão psíquica geracional. 


\section{Abstract}

Jucá-Vasconcelos, Helena Pinheiro; Féres-Carneiro, Terezinha (Advisor). Domestic Violence and Generational Psychic Transmission. Rio de Janeiro, 2011, 112p. MSc. Dissertation - Departamento de Psicologia, Pontifícia Universidade Católica do Rio de Janeiro.

This study aims at evaluating the possible relationship between domestic violence and generational psychic transmission. It is relevant due to the high prevalence of violence against women, and because this is actually considered a public health problem. The main objective was to investigate the possible transmission of violence from one generation to another and its probable resonance. It examines what types of violence the victims suffered and how they conceptualized it. To achieve the objectives, a qualitative fieldwork was carried out interviewing nine women victims of physical violence by intimate partners through means of Internet chat conferences. The procedure used was the Underlying Discourse Unveiling Method (UDUM). The results indicate a clear repetition of violence among family members, from the standpoint of the perpetrator and of the victim.

\section{Keywords}

Domestic violence; violence against women; psychic transmission between generations. 


\section{Sumário}

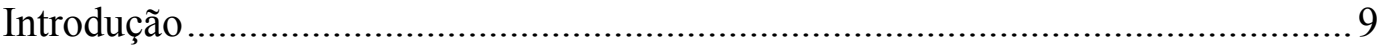

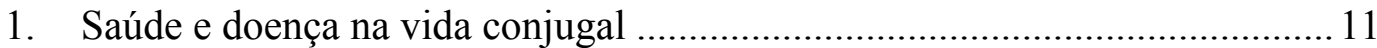

1.1. Relacionamento conjugal: construção de diferenças e de ambivalências .. .11

1.2. Relacionamento conjugal enquanto experiência saudável....................22

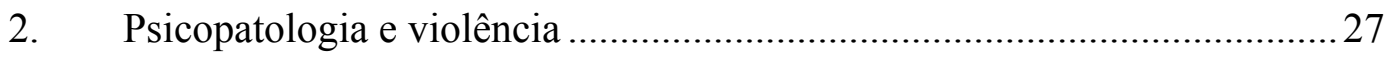

2.1. As várias faces do masoquismo: sadomasoquismo e comportamentos

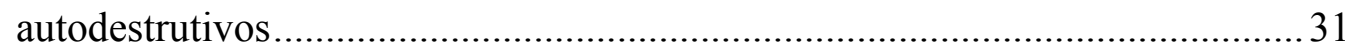

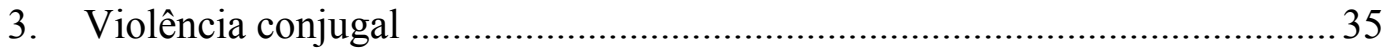

3.1. Violência e saúde da mulher e da família ............................................ 40

3.2. Modalidades de violência ..................................................................... 41

3.3. Papel de cada um na violência .......................................................... 47

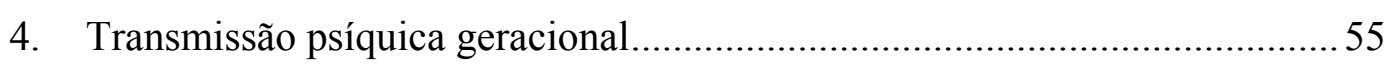

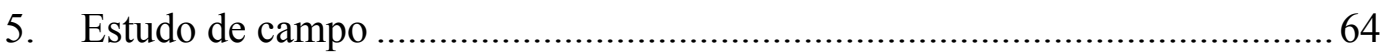

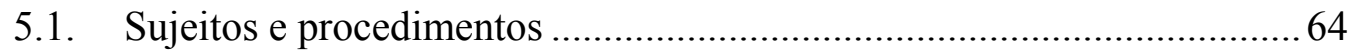

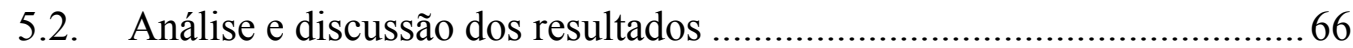

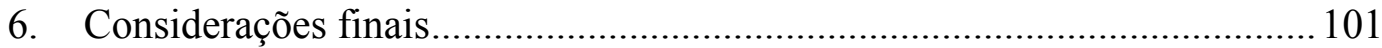

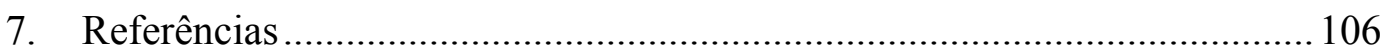

